\title{
Analisis Rasio CAMEL (Capital, Asset, Management, Earnings, Equity dan Liquidity) pada Tingkat Kesehatan Bank (Studi Kasus BRI Syariah Periode 2018-2019)
}

\author{
Widi Savitri Andriasari'1, Siti Ummi Munawaroh² \\ Institut Agama Islam Negeri Kudus ${ }^{12}$ \\ andriawidi@iainkudus.ac.id ${ }^{1}$, unaputrimunawaroh@gmail.com²
}

\begin{abstract}
This study aims to determine the results of the CAMEL ratio analysis (Capital, Asset Quality, Management, Earnings and Liquidity) at the soundness level of a Sharia BRI Bank for the period 2018-2019. The soundness level of a bank is an assessment conducted by the OJK for each bank to determine whether the bank is in good health or not. Regulations regarding the assessment of the level of health at commercial banks are contained in Bank Indonesia Regulation Number 13/1/PBI/2011 and Financial Services Authority Regulation Number 8/POJK.03/2014 and Financial Services Authority Regulation Number 4/POJK.03/2016. This type of research is a descriptive study with a quantitative approach. Descriptive research method is the method used to describe the research results by analyzing data from financial statement sources. While the quantitative research method is a study that uses data in the form of numbers as a means of analyzing and calculating. For this reason, the source of data needed in this study is secondary data which is the financial statements of a Sharia BRI Bank for the period 2018-2019. Through the data source in the form of financial reports can find out the soundness level of BRI Syariah Bank in 2018-2019 by calculating and analyzing the CAMEL ratio.
\end{abstract}

Keywords: Islamic Bank, CAMEL Ratio, Bank Soundness Level.

\begin{abstract}
Abstrak
Penelitian ini bertujuan untuk mengetahui hasil analisis rasio CAMEL (Capital, Asset Quality, Management, Earnings dan Liquidity) pada tingkat kesehatan bank BRI Syariah periode 2018-2019. Tingkat kesehatan bank ini adalah penilaian yang dilakukan oleh OJK kepada setiap bank untuk mengetahui apakah bank tersebut dalam keadaan sehat atau tidak. Regulasi mengenai penilaian tingkat kesehatan pada bank umum terdapat pada peraturan Bank Indonesia Nomor 13/1/PBI/2011 dan Peraturan Otoritas Jasa Keuangan Nomor 8/POJK.03/2014 dan Peraturan Otoritas Jasa Keuangan Nomor 4/POJK.03/2016. Jenis penelitian ini adalah penelitian deskriptif dengan pendekatan kuantitatif. Metode penelitian deskriptif yaitu metode yang digunakan untuk menggambarkan hasil penelitian dengan cara menganalisis data-data dari sumber laporan keuangan. Sedangkan metode penelitian kuantitatif merupakan penelitian yang menggunakan data berupa angka sebagai alat menganalisis dan perhitungan. Untuk itu, sumber data yang diperlukan dalam penelitian ini adalah data sekunder yang merupakan laporan keuangan Bank BRI Syariah periode 2018-2019. Melalui sumber data berupa laporan keuangan tersebut dapat mengetahui tingkat kesehatan Bank BRI Syariah pada tahun 20182019 dengan menghitung dan menganalisis rasio CAMEL.
\end{abstract}

Kata Kunci: Bank Syariah, Rasio CAMEL, Tingkat Kesehatan Bank. 


\section{PENDAHULUAN}

Perkembangan dari perbankan syariah di Indonesia dimulai sejak tahun 1983 bersamaan dengan lahirnya beberapa regulasi perbankan. Saat itu, pemerintah Indonesia berencana agar menerapkan sistem bagi hasil dalam perkreditan yang merupakan konsep perbankan syariah. Kemudian, pada tahun 1980 muncul sejumlah inisiatif untuk mendirikan bank Islam di Indonesia melalui diskusi-diskusi yang bertemakan bank Islam sebagai pilar ekonomi Islam. Dan pada tahun 1988, muncullah beberapa bank konvensional dan bank daerah yang berasaskan syariah. Pada tahun 1990, bank Islam di Indonesia terlihat semakin masif sehingga Majelis Ulama Indonesia (MUI) membentuk kelompok kerja untuk mendirikan Bank Islam di Indonesia. Dengan hasil kinerja dari MUI tersebut, maka berdirilah bank syariah pertama kali di Indonesia yaitu Bank Muamalat Indonesia yang diresmikan pada tahun. Enam tahun sejak diresmikannya Bank Muamalat Indonesia ini, barulah pemerintah menyempurnakan Undang-Undang dari UU No. 7 Tahun 1992 tersebut menjadi UU No.10 Tahun 1998 yang berisi penegasan bahwa terdapat dua sistem dalam perbankan di tanah air (dual banking system), yaitu sistem perbankan konvensional dan sistem perbankan syariah. Sejak itu, masyarakat menyambutnya dengan hangat dan mulai tertarik akan perbankan syariah. Dan diperkuat dengan ditandainya berdirinya beberapa bank Islam lainnya seperti Bank IFI, Bank Syariah Mandiri, Bank Niaga, Bank BTN, Bank Mega, Bank BRI, Bank Bukopin, BPD Jabar dan BPD Aceh dan lainnya. Sejalan dengan itu, ada berbagai pengesahan produk perundangan dan perubahan Undang-Undang lama untuk lebih spesifik tentang bank syariah dapat memberikan kepastian hukum. Hal ini dibuktikan dengan perubahan UU No.10 Tahun 1998 menjadi UU No. 21 Tahun 2008. Dengan UU tersebut, maka akan menjadi tonggak utama dalam meningkatkan dan mengembangkan perbankan syariah di Indonesia.

Perkembangan perbankan syariah di Indonesia dari tahun ke tahun mengalami peningkatan, meskipun tidak cukup signifikan. Dari data Snapshot OJK per Juni 2019, menunjukkan bahwa market share dari perbankan syariah yaitu sebesar 5,95\%. Untuk itu, agar market share perbankan syariah terus meningkat, setiap bank syariah harus meningkatkan kualitas kinerjanya. Kinerja suatu bank syariah perlu diperhatikan dan dijaga agar tingkat kesehatan bank dapat berjalan dengan baik. Tingkat kesehatan bank salah satu point dan target penting yang harus dicapai dan diraih setiap bank baik bank umum konvensional maupun bank umum syariah. Bank dapat dikatakan sehat apabila bank tersebut dapat melaksanakan kontrol terhadap aspek modal, aktiva, rentabilitas, manajemen dan aspek likuiditasnya.

Permana (2012) Bank yang sehat adalah bank yang dapat menjalankan fungsi-fungsinya dengan baik seperti dapat menjaga kepercayaan masyarakat, dapat menjalankan fungsi intermediasi, dapat membantu kelancaran lalu lintas pembayaran, serta dapat melaksanakan kebijakan 
Analisis Rasio CAMEL (Capital, Asset, Management, Earnings, Equity dan Liquidity) pada Tingkat Kesehatan Bank (Studi Kasus BRI Syariah Periode 2018-2019)

moneter. Menurut Peraturan Otoritas Jasa Keuangan (POJK) No.8/POJK.03/2014 pengertian kesehatan bank merupakan sarana bagi otoritas pengawas dalam menetapkan strategi dan fokus pengawasan terhadap bank. Perubahan kompleksitas usaha dan profil risiko yang dapat berasal dari bank serta perubahan pendekatan penilaian kondisi bank yang diterapkan secara internasional mempengaruhi pendekatan penilaian tingkat kesehatan bank. Tingkat kesehatan bank menurut POJK No. 8/POJK.03/2014 adalah hasil penilaian kondisi bank yang dilakukan berdasarkan risiko termasuk risiko terkait penerapan prinsip syariah dan kinerja bank atau disebut Risk-based Bank Rating. Dalam pengukuran tingkat kesehatan bank ada beberapa cara, salah satunya menggunakan metode CAMEL (Capital, Asset Quality, Management, Earning and Liquidity). Penelitian mengenai tingkat kesehatan suatu bank sebelumnya telah dilakukan oleh Erros Daniarga yang meneliti tentang adanya pengaruh rasio CAMEL terhadap tingkat kesehatan bank yang nantinya akan mempengaruhi pertumbuhan laba pada perusahaan sektor perbankan. Karena, dengan adanya bank yang sehat ini, maka akan menghasilkan laba yang optimal.

Tujuan dari penelitian ini adalah untuk mengetahui analisis rasio CAMEL (Capital, Asset Quality, Management, Earning and Liquidity) pada kesehatan dari Bank BRI Syariah pada periode 2018-2019. Dengan menganalisis rasio CAMEL ini, akan menentukan apakah Bank BRI Syariah dalam kondisi sehat, cukup sehat, kurang sehat atau tidak sehat. Ada beberapa rasio yang digunakan untuk mengukur tingkat kesehatan bank, diantaranya ada rasio capital, yang digunakan untuk mengukur kemampuan bank menggunakan modalnya sendiri. Lalu, rasio asset yang digunakan untuk mengukur kemampuan efisiensi keuangan. Ada juga rasio management yang digunakan untuk mengetahui kegiatan manajemennya. Selain itu, ada rasio earnings yang digunakan untuk mengukur perolehan laba dari bank BRI Syariah. Dan yang terakhir, adalah rasio liquidity yang digunakan untuk melihat kemampuan bank untuk membayar, terutama membayar pinjaman jangka pendek. Berdasarkan uraian tersebut, maka penulis tertarik untuk membuat karya ilmiah dengan judul "Analisis CAMEL Terhadap Tingkat Kesehatan Bank (Studi Kasus BRI Syariah Periode 2018-2019)”.

\section{KAJIAN LITERATUR}

\section{A. Pengertian Bank Syariah}

Bank merupakan badan usaha yang menghimpun dana dari masyarakat dalam bentuk simpanan dan menyalurkannya kepada masyarakat dalam bentuk kredit dan/atau bentuk lainnya dalam rangka meningkatkan taraf hidup rakyat. Sedangkan perbankan syariah dalam UU Nomor 21 Tahun 2008 adalah segala sesuatu yang menyangkut tentang bank syariah dan Unit Usaha Syariah (UUS), mencakup kelembagaan, kegiatan usaha, serta cara dan proses dalam melaksankaan kegiatan usahanya. Jadi, dalam hal ini, perbankan syariah merupakan 
suatu lembaga intermediasi penghimpunan dana dari pihak yang kelebihan dana (surplus) dan menyalurkannya ke pihak yang kekurangan dana (defisit) dengan didasari oleh hukum Islam (syariah). Dalam artian, perbankan syariah melarang adanya prinsip bunga yang identik dengan riba (Nopita Sari, 2018:24). Disini, perbankan syariah hadir sebagai alternatif dari bank konvensional bagi masyarakat yang enggan menggunakan perbankan konvensional yang terindikasi mengandung unsur riba. Perbankan syariah lebih menerapkan prinsip keadilan yaitu bagi hasil atau nisbah yang prosesnya sama-sama diketahui dan disetujui oleh pihak bank dan pihak nasabah.

\section{B. Pengertian Tingkat Kesehatan Bank}

Tingkat kesehatan suatu bank merupakan salah satu aspek yang paling penting yang harus diketahui oleh stakeholder. Secara sederhana, bank yang sehat adalah bank yang dapat menjalankan fungsinya dengan baik dalam mengelola dana dari masyarakat yang dipercayakan kepada kepada bank, dapat menjalankan fungsinya sebagai lembaga intermediasi, dapat membatu kelancaran lalu lintas pembayaran, serta dapat digunakan oleh pemerintah dalam melaksanakan kebijakannya, terutama kebijakan moneter. Bank Indonesia sebagai bank sentral mempunyai peranan penting dalam mengatur tingkat kesehatan bank, baik bank syariah maupun bank konvensional dan mempunyai peranan untuk merumuskan serta mengatur kebijakan sesuai dengan isu ekonomi global terkini. Bagi perbankan konvensional dan perbankan syariah, penilaian tingkat kesehatan dapat digunakan sebagai salah satu alat bagi manajemen dalam menentukan kebijakan dan pelaksanaan pengelolaan bank ke depan. Sementara bagi Bank Indonesia, hasil penilaian tingkat kesehatan bank dapat digunakan oleh pengawas dalam menerapkan strategi pembinaan, pengembangan dan pengawasan yang tepat bagi bank Syariah (Usman R, 2012:364).

Dengan hasil penilaian bank yang sehat, maka dapat memberikan sinyal positif bagi bank agar stakeholers mau berinvestasi di bank tersebut. Oleh karena itu, semakin tinggi tingkat kesehatan bank maka akan mempengaruhi harga saham bank di pasar saham. Penilaian tingkat kesehatan bank dapat dilakukan dengan cara menganalisis laporan keuangan pada perbankan tersebut. Hal ini dikarenakan bahwa laporan keuangan merupakan sarana yang menyediakan informasi keuangan sebagai bahan pertimbangan saat mengambil keputusan (Hafiz A.P, 2018:66-67).

Ada 4 kategori dalam penggolongan tingkat kesehatan bank, yaitu kategori sehat, cukup sehat, kurang sehat dan tidak sehat. Berikut merupakan penggolongan tingkat kesehatan bank menurut CAMEL: 
Analisis Rasio CAMEL (Capital, Asset, Management, Earnings, Equity dan Liquidity) pada Tingkat Kesehatan Bank (Studi Kasus BRI Syariah Periode 2018-2019)

Tabel. 1

Tingkat Kesehatan Bank Menurut CAMEL

\begin{tabular}{|c|c|}
\hline Nilai Kredit CAMEL (Bobot) & Predikat \\
\hline $81 \%-100 \%$ & Sehat \\
\hline $66 \%-<81 \%$ & Cukup Sehat \\
\hline $51 \%-<66 \%$ & Kurang Sehat \\
\hline $0 \%-<51 \%$ & Tidak Sehat \\
\hline
\end{tabular}

\section{Rasio Pengukuran Tingkat Kesehatan Bank}

Rasio CAMEL menurut Kamus Perbankan Bank Indonesia (2015), yaitu aspek yang paling berpengaruh terhadap kondisi keuangan bank dan mempengaruhi tingkat kesehatan bank, baik itu perbankan konvensional maupun perbankan Syariah (Syahputra, 2018:51). Rasio CAMEL nantinya akan menggambarkan suatu hubungan atau perbandingan antara suatu jumlah tertentu dengan jumlah yang lain. Oleh karena itu, dengan analisis rasio nantinya dapat diperoleh gambaran mengenai baik atau buruknya posisi keuangan suatu bank (Paputungan, 2016:733). Menurut Kasmir (2002), salah satu alat yang digunakan untuk mengukur kesehatan bank adalah dengan menganalisis CAMEL, yaitu :

1. Capital

Capital merupakan rasio penilaian yang didasari atas permodalan yang dimiliki suatu bank, yaitu dengan menggunakan CAR (Capital Adequacy Ratio) dengan membandingkan modal terhadap aktiva tertimbang (ATMR). Setiap bank yang beroperasi di Indonesia, baik bank konvensional maupun bank syariah diwajibkan untuk memelihara Kewajiban Penyediaan Modal Minimum (KPMM) sekurang-kurangnya 8\% (Riyadi S, 2006:171). Berikut ini rumus yang digunakan dalam menghitung modal suatu bank:

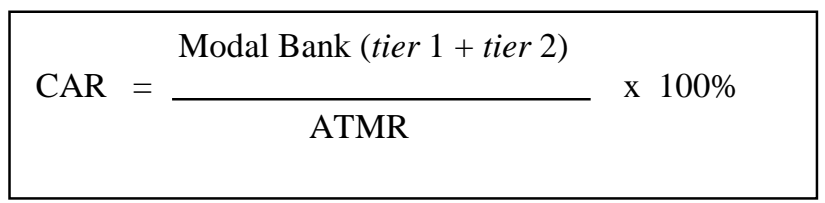

Dengan nilai kredit:

$$
\text { Nilai Kredit }=\frac{\begin{array}{c}
\text { Rasio CAR } \\
+1
\end{array}}{0,1 \%}
$$


2. Asset

Asset merupakan rasio penilaian yang didasari atas kualitas aktiva yang dimiliki suatu bank. Rasio yang diukur dalam penilaian ini yaitu rasio aktiva produktif yang diklasifikasikan terhadap aktiva produktif (Prasetyoningrum AK, 2016:61). Berikut ini merupakan rumus untuk mengukur tingkat kesehatan bank dalam segi asetnya:

$$
\mathrm{KAP}=\frac{\text { Aktiva Produktif yang Diklasifikasikan }}{\text { Total Aktiva Produktif }} \times 100 \%
$$

Dengan nilai kredit:

$$
\text { Nilai Kredit }=\frac{\begin{array}{c}
15,5 \%-\text { Rasio KAP } \\
+1
\end{array}}{0,15 \%}
$$

\section{Management}

Management merupakan rasio penilaian suatu bank yang didasari atas manajemen permodalan, manajemen aktiva, manajemen rentabilitas, manajemen likuiditas dan manajemen umum. Berdasarkan hal tersebut, maka rumus yang digunakan untuk menghitung tingkat kesehatan bank dalam sisi manajemennya, yaitu:

$$
\mathrm{NPM}=\frac{\text { Laba Bersih }}{\text { Pendapatan Operasional }} \times 100 \%
$$

\section{Earning}

Earning yaitu rasio penilaian yang didasari atas rentabilitas suatu bank atau kemampuan bank dalam menghasilkan laba. Untuk mengukur kemampuan bank dalam menghasilkan laba, yaitu diukur dengan Return on Asset (ROA) dan Beban Operasional terhadap Pendapatan Operasional (BOPO). Dibawah ini merupakan rumus untuk menghitung rentabilitas bank:

a. Rasio Laba terhadap Total Aset (ROA)

$$
\text { ROA }=\frac{\text { Laba Bersih Sebelum Pajak }}{\text { Total Aktiva }} \times 100 \%
$$


Analisis Rasio CAMEL (Capital, Asset, Management, Earnings, Equity dan Liquidity) pada Tingkat Kesehatan Bank (Studi Kasus BRI Syariah Periode 2018-2019)

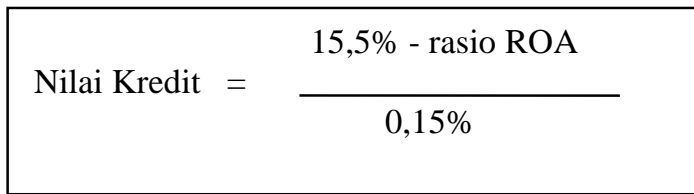

b. Rasio Beban Operasional terhadap Pendapatan Operasional (BOPO), (L. Wilson, 2016:698)

$$
\text { BOPO }=\frac{\text { Beban Operasional }}{\text { Pendapatan Operasional }} \times 100 \%
$$

$$
\text { Nilai Kredit }=\frac{100 \%-\text { rasio BOPO }}{0,08 \%}
$$

5. Liquidity

Liquidity (Kurniawan W, 2017:80) yaitu rasio yang digunakan untuk menilai likuiditas suatu bank yaitu dengan melihat pembiayaan masyarakat terhadap dana yang diterima oleh bank (Finacing to Deposit Ratio), Berikut ini rumus yang digunakan untuk menghitung likuiditas suatu bank:

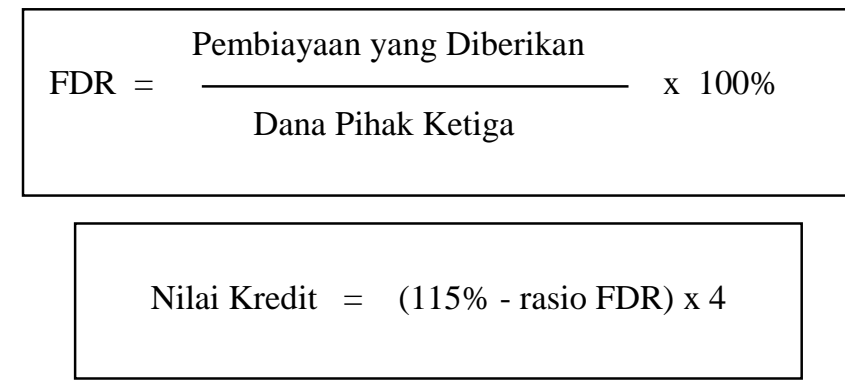

Tabel. 2

Rasio Tingkat Kesehatan Bank dengan Rasio CAMEL

\begin{tabular}{|c|c|c|c|c|c|c|}
\hline Kriteria & CAR & KAP & NPM & ROA & BOPO & FDR \\
\hline Sehat & $>8 \%$ & $\begin{array}{c}0 \%- \\
10,35 \%\end{array}$ & $\begin{array}{c}<100 \%- \\
\geq 81 \%\end{array}$ & $\geq 1,215 \%$ & $\leq 93,52 \%$ & $\leq 94,75 \%$ \\
\hline Cukup & $7,99 \%-$ & $10,35 \%$ & $81 \%-$ & $\geq 0,99 \%-$ & $>93,52 \%$ & $\geq 94,75 \%-$ \\
Sehat & $8 \%$ & $-12,6 \%$ & $66 \%$ & $1,21 \%$ & - & $<98,50 \%$ \\
& & & & & $\leq 94,72 \%$ & \\
\hline Kurang & $6,5 \%-$ & $12,6 \%-$ & $51 \%-$ & $\geq 0,76 \%-$ & $>94,72 \%$ & $\geq 98,50 \%-$ \\
Sehat & $7,99 \%$ & $14,5 \%$ & $66 \%$ & $0,99 \%$ & - & $<102,25 \%$ \\
& & & & & $\leq 95,92 \%$ & \\
\hline $\begin{array}{c}\text { Tidak } \\
\text { Sehat }\end{array}$ & $\leq 6,5 \%$ & $>14,5 \%$ & $<51 \%$ & $<0,766 \%$ & $>95,92 \%$ & $>102,25 \%$ \\
\hline
\end{tabular}




\section{METODE PENELITIAN}

Penelitian ini menggunakan metode kuantitatif, dengan menggunakan data-data berupa angka nominal sebagai alat menganalisis dan menghitung. Sedangkan jenis penelitian ini merupakan penelitian deskriptif, yaitu penelitian yang menggambarkan atau menganalisis suatu hasil penelitian dengan cara menganalisis data dari sumber laporan keuangan yang menggunakan metode CAMEL (Capital, Asset, Management, Earning dan Liquidity). Adanya penelitian ini bertujuan untuk menentukan apakah Bank BRI Syariah dalam kondisi sehat, cukup sehat, kurang sehat atau tidak sehat. Sedangkan jenis data yang digunakan dalam penelitian ini adalah data sekunder yang diperoleh dari laporan keuangan Bank BRI Syariah periode 2018-2019, data snapshot perbankan tahun 2018 dan 2019, buku-buku, jurnal penelitian sebelumnya dan referensi lainnya yang berkaitan dengan analisis rasio CAMEL pada tingkat kesehatan Bank BRI Syariah.

\section{HASIL DAN PEMBAHASAN}

\section{Hasil Penelitian}

Berikut ini adalah hasil perhitungan CAMEL (Capital, Asset, Management, Earnings, Equity dan Liquidity) terhadap tingkat kesehatan BRI Syariah periode 2018 dan 2019:

a. Rasio Capital (Kecukupan Modal)

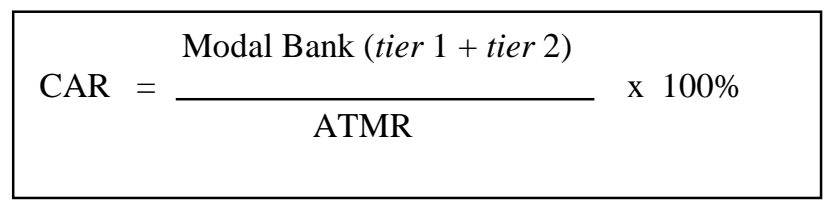

Perhitungan rasio CAR dan nilai kredit pada tahun 2018:

$$
\begin{aligned}
& \text { CAR }=\quad \frac{5.922 .283 \text { juta }}{19.928 .066 \text { juta }} \times 100 \% \\
& =\quad 0,2972 \times 100 \% \\
& =\quad 29,72 \% \\
& \begin{aligned}
\text { Nilai Kredit } & =(\text { Rasio }: 0,1)+1 \\
& =(28,82: 0,1)+1 \\
& =289 \%
\end{aligned}
\end{aligned}
$$

Perhitungan rasio CAR dan nilai kredit pada tahun 2019:

$$
\begin{aligned}
& \text { CAR }=\frac{5.812 .183 \text { juta }}{23.012 .092 \text { juta }} \times 100 \% \\
& =\quad 0,2529 \times 100 \% \\
& =\quad 25,29 \% \\
& \begin{aligned}
\text { Nilai Kredit } & =(\text { Rasio }: 0,1)+1 \\
& =(25,29: 0,1)+1 \\
& =253,9 \%
\end{aligned}
\end{aligned}
$$


Analisis Rasio CAMEL (Capital, Asset, Management, Earnings, Equity dan Liquidity) pada Tingkat Kesehatan Bank (Studi Kasus BRI Syariah Periode 2018-2019)

b. Rasio Asset (Kualitas Aktiva Produktif)

$$
\mathrm{KAP}=\frac{\text { Aktiva Produktif yang Diklasifikasikan }}{\text { Total Aktiva Produktif }} \times 100 \%
$$

Perhitungan rasio KAP dan nilai kredit pada tahun 2018:

$$
\begin{aligned}
& \text { KAP }=\quad \frac{364.360 \text { juta }}{9.247 .836 \text { juta }} \times 100 \% \\
& =\quad 0,0393 \times 100 \% \\
& =\quad 3,93 \% \\
& \begin{aligned}
\text { Nilai Kredit } & =((15,5 \%-\text { rasio }): 0,15 \%)+1 \\
& =((15,5 \%-3,93 \%): 0,15 \%)+1 \\
& =100,27 \%
\end{aligned}
\end{aligned}
$$

Perhitungan rasio KAP dan nilai kredit pada tahun 2019:

$$
\begin{aligned}
& \text { KAP }=\frac{524.101 \text { juta }}{12.828 .426 \text { juta }} \times 100 \% \\
& =\quad 0,0408 \times 100 \% \\
& =\quad 4,08 \% \\
& \begin{aligned}
\text { Nilai Kredit } & =((15,5 \%-\text { rasio }): 0,15 \%)+1 \\
& =((15,5 \%-4,08 \%): 0,15 \%)+1 \\
& =100,12 \%
\end{aligned}
\end{aligned}
$$

c. Rasio Management (Kualitas Manajemen)

$$
\mathrm{NPM}=\frac{\text { Laba Bersih }}{\text { Pendapatan Operasional }} \times 100 \%
$$

Perhitungan rasio NPM dan nilai kredit pada tahun 2018:

$$
\begin{aligned}
\mathrm{NPM} & =\frac{106.600 \text { juta }}{174.182 \text { juta }} \times 100 \% \\
& =0,6120 \times 100 \% \\
& =61,20 \%
\end{aligned}
$$

Perhitungan rasio NPM dan nilai kredit pada tahun 2019:

$$
\begin{aligned}
\text { NPM } & =\frac{74.016 \text { juta }}{250.534 \text { juta }} \times 100 \% \\
& =0,2954 \times 100 \%
\end{aligned}
$$




$$
=29,54 \%
$$

d. Rasio Earnings (Kemampuan Menghasilkan Laba)

ROA $=\frac{\text { Laba Bersih Sebelum Pajak }}{\text { Total Aktiva }} \times 100 \%$

Perhitungan rasio ROA dan nilai kredit pada tahun 2018:

$$
\begin{aligned}
& \text { ROA }=\frac{151.514 \text { juta }}{37.869 .177 \text { juta }} \times 100 \% \\
& =\quad 0,004 \times 100 \% \\
& =\quad 0,4 \% \\
& \text { Nilai Kredit }=(15,5 \%-\text { rasio) }: 0,15 \% \\
& =(15,5 \%-0,4 \%): 0,15 \% \\
& =100,67 \%
\end{aligned}
$$

Perhitungan rasio ROA dan nilai kredit pada tahun 2019:

$$
\begin{aligned}
\text { ROA }= & \frac{116.865 \text { juta }}{43.123 .488 \text { juta }} \times 100 \% \\
= & 0,0027 \times 100 \% \\
= & 0,27 \% \\
\text { Nilai Kredit } & =(15,5 \%-\text { rasio) }: 0,15 \% \\
& =(15,5 \%-0,27 \%): 0,15 \% \\
& =101,53 \%
\end{aligned}
$$

$$
\mathrm{BOPO}=\frac{\text { Beban Operasional }}{\text { Pendapatan Operasional }} \times 100 \%
$$

Perhitungan rasio BOPO dan nilai kredit pada tahun 2018:

$$
\begin{aligned}
\text { BOPO }= & \frac{1.864 .830 \text { juta }}{3.294 .489 \text { juta }} \times 100 \% \\
=\quad & 0,5660 \times 100 \% \\
= & 56,60 \% \\
\text { Nilai Kredit } & =(100 \%-\text { rasio }): 0,08 \% \\
& =(100 \%-56,60 \%): 0,08 \% \\
& =542,5 \%
\end{aligned}
$$

Perhitungan rasio BOPO dan nilai kredit pada tahun 2019:

$$
\mathrm{BOPO}=\frac{2.187 .646 \text { juta }}{100 \%}
$$


Analisis Rasio CAMEL (Capital, Asset, Management, Earnings, Equity dan Liquidity) pada Tingkat Kesehatan Bank (Studi Kasus BRI Syariah Periode 2018-2019)

$$
\begin{array}{ll} 
& 3.625 .397 \text { juta } \\
= & 0,6034 \times 100 \% \\
= & 60,34 \%
\end{array}
$$

Nilai Kredit $=(100 \%-$ rasio $): 0,08 \%$

$$
\begin{aligned}
& =(100 \%-60,34 \%): 0,08 \% \\
& =495,75 \%
\end{aligned}
$$

e. Rasio Liquidity (Kemampuan Menjamin Likuiditas)

$\mathrm{FDR}=\frac{\text { Pembiayaan yang Diberikan }}{\text { Dana Pihak Ketiga }} \times 100 \%$

Perhitungan rasio FDR dan nilai kredit pada tahun 2018:

$$
\begin{aligned}
& \text { FDR }=\frac{21.860 .000 \text { juta }}{28.860 .000 \text { juta }} \times 100 \% \\
& =\quad 0,7574 \times 100 \% \\
& =\quad 75,74 \% \\
& \begin{aligned}
\text { Nilai Kredit } & =(115 \%-\text { rasio FDR }) \times 4 \\
& =(115 \%-75,74 \%) \times 4 \\
& =157,04 \%
\end{aligned}
\end{aligned}
$$

Perhitungan rasio FDR dan nilai kredit pada tahun 2019:

$$
\begin{aligned}
\text { FDR } & =\frac{27.380 .000 \text { juta }}{34.120 .000 \text { juta }} \times 100 \% \\
& =0,8025 \times 100 \% \\
& =80,25 \%
\end{aligned}
$$

Nilai Kredit $=(115 \%-$ rasio FDR $) \times 4$

$$
\begin{aligned}
& =(115 \%-80,25 \%) \times 4 \\
& =139 \%
\end{aligned}
$$

\section{Pembahasan Penelitian}

Berikut ini adalah hasil analisis pengaruh CAMEL (Capital, Asset, Management, Earnings, Equity dan Liquidity) terhadap tingkat kesehatan BRI Syariah periode 2018 dan 2019:

a. Rasio Capital (Kecukupan Modal)

Besarnya permodalan bank syariah dipengaruhi atas kemampuan bank dalam pemenuhan Kewajiban Pemenuhan Modal Minimum (KPMM). Standar yang ditetapkan oleh Bank Indonesia tentang penyediaan modal minimum ini yaitu sebesar 8\%. Rasio Capital Adequacy Ratio (CAR) ini digunakan untuk mengukur seberapa kuat permodalan bank menutupi risiko (risiko 
kredit, risiko operasional dan risiko pasar) yang ada pada suatu bank. Dalam (Kurniawan W,2016:698) untuk menghitung CAR, kita cukup membandingkan modal terhadap Aktiva Tertimbang Menurut Risiko (ATMR).

Pada periode 2018, rasio permodalan BRI Syariah sebesar $29,72 \%$. Sedangkan pada tahun 2019, rasio permodalan BRI Syariah mencapai 25,29\% menurun dari tahun sebelumnya. Meskipun mengalami penurunan, tetapi penurunannya tidak signifikan. Hal ini membuktikan bahwa BRI Syariah memiliki modal yang cukup untuk menutup segala risiko pasar, risiko kredit dan risiko operasional. Untuk itu, rasio permodalan dari BRI Syariah termasuk dalam kategori "Sehat" karena nilai CAR berada diatas ketentuan Bank Indonesia.

Sedangkan nilai kredit aspek CAR yang dicapai oleh BRI Syariah pada tahun 2018 yaitu sebesar $289 \%$ dan pada tahun 2019 nilai kreditnya yaitu mencapai 253,9\%. Walaupun nilai kredit pada tahun 2018 dan 2019 melebihi 100\%, nilai kredit dibatasi maksimal 100\%. Maka, nilai kredit aspek CAR BRI Syariah periode 2018 dan 2019 nilai kreditnya diakui sebesar 100\%. Sehingga dapat disimpulkan bahwa aspek permodalan BRI Syariah mendapat predikat "Sehat".

Semakin tinggi rasio permodalannya, maka semakin sehat bank tersebut. Jika, CAR suatu bank tinggi, tingkat kepercayaan masyarakat terhadap bank juga semakin besar, sehingga dapat meningkatkan nilai saham tersebut. Dengan CAR yang tinggi, maka suatu bank seperti BRI Syariah mampu membiayai kegiatan operasional dan mampu memberikan kontribusi yang cukup besar bagi profitabilitas.

b. Rasio Asset (Kualitas Aktiva Produktif)

Rasio aset merupakan ukuran untuk menilai tingkat efisiensi bank dalam memanfaatkan sumber daya yang dimilikinya atau jenis-jenis aset yang dimiliki oleh bank. Penilaian terhadap rasio aset yaitu dengan menghitung nilai Kualitas Aktiva Produktif (KAP). Rasio KAP digunakan untuk mengukur tingkat kemungkinan diterimanya kembali dana yang ditanamkan. Semakin rendah rasio KAP-nya, maka semakin tinggi probabilitas diterimanya kembali dana yang ditanamkan.

Dalam hal ini, Kualitas Aktiva Produktif (KAP) yang dimiliki oleh BRI Syariah pada tahun 2018 yaitu sebesar 3,93\% dengan nilai kredit 100,27\%. Dan pada tahun 2019, rasio Kualitas Aktifa Produktif (KAP) yang dimiliki oleh BRI Syariah yaitu sebesar 4,08\% dengan nilai kredit 100,12\%. Hal ini menunjukkan bahwa KAP BRI Syariah pada tahun 2018 dan 2019 memperoleh predikat "sehat" karena nilai KAP-nya dibawah 10,35\%. Sehingga, dapat dikatakan bahwa BRI Syariah mampu mengelola kualitas aktiva 
Analisis Rasio CAMEL (Capital, Asset, Management, Earnings, Equity dan Liquidity) pada Tingkat Kesehatan Bank (Studi Kasus BRI Syariah Periode 2018-2019)

produktifnya dengan tujuan untuk mendapatkan penghasilan yang maksimal.

c. Rasio Management (Kualitas Manajemen)

Dalam hal ini, penilaian manajemen dilakukan dengan menggunakan rasio Net Profit Margin (NPM) yang menggambarkan tingkat keuntungan bank dibandingkan dengan pendapatan yang diterima dari kegiatan operasionalnya. Dari analisis data tersebut, dapat disimpukan bahwa rasio Net Profit Margin (NPM) pada BRI Syariah periode 2018 yaitu memperoleh nilai sebesar 61,20\% dan pada tahun 2019 memperoleh Net Profit Margin (NPM) sebesar 29,54\%. BRI Syariah ternyata mengalami penurunan Net Profit Margin (NPM) yang cukup signifikan yaitu sebesar 31,66\%. Oleh karena itu, BRI Syariah mendapatkan predikat "tidak sehat" dengan alasan bahwa rasio Net Profit Margin (NPM) pada bank tersebut masih dibawah ketentuan Bank Indonesia. Hal ini menunjukkan bahwa BRI Syariah belum mampu untuk mengelola sumber daya secara efektif dan efisien sehingga BRI Syariah belum menghasilkan laba bersih yang maksimal pada tahun 2018 dan 2019.

d. Rasio Earnings (Kemampuan Menghasilkan Laba)

Pada rasio earnings (rentabilitas) ini yang dinilai adalah kemampuan bank dalam meningkatkan laba dan efisiensi usaha yang dicapai. Dalam hal ini, kita bisa menghitung rasio ROA bank tersebut. ROA menunjukkan kemampuan manajemen bank dalam menghasilkan laba dari pengelolaan aset yang dimilikinya. Semakin tinggi rasio ROA pada bank, maka semakin rendah probabilitas bank mengalami kebangkrutan. Selain ROA, kita juga dapat mengukur rasio earnings dengan menggunakan BOPO. Rasio BOPO ini adalah rasio perbandingan antara biaya operasional dengan pendapatan operasional. Maka, semakin rendah rasio BOPO-nya berarti semakin baik kinerja manajemen bank sehingga akan mendapatkan laba yang maksimal.

Berdasarkan hasil perhitungan diatas, BRI Syariah pada tahun 2018 rasio ROA-nya yaitu sebesar 0,4\% dengan nilai kredit sebesar $100,67 \%$ dan pada tahun 2019 rasio ROA-nya yaitu sebesar $0,27 \%$ dengan nilai kredit 101,53\%. Dalam hal ini terdapat penurunan sebesar $0,13 \%$. Walaupun penurunan rasio ROA tidak signifikan, tetapi dalam hal ini BRI Syariah tetap mendapatkan predikat "tidak sehat" yang dikarenakan rasio ROA-nya masih dibawah 1,215\%. Hal ini menggambarkan bahwa BRI Syariah belum memiliki kemampuan untuk menghasilkan laba dari total aktiva yang dimilikinya.

Sedangkan untuk rasio BOPO-nya, BRI Syariah pada tahun 2018 memperoleh nilai BOPO sebesar 56,60\% dengan nilai kredit 
sebesar 542,5\%. Lalu, pada tahun 2019 rasio BOPO pada BRI Syariah mengalami peningkatan yaitu menjadi $60,34 \%$ dengan nilai kredit sebesar 495,75\%. Dengan hasil perhitungan tersebut, menunjukkan bahwa rasio BOPO pada BRI Syariah periode 2018 dan 2019 dikategorikan "sehat" karena hasil perhitungan rasio BOPO tersebut tidak melebihi batas dari ketentuan Bank Indonesia yaitu sebesar 93,52\%. Sehingga, dapat disimpulkan bahwa BRI Syariah dalam melakukan kegiatan operasionalnya, BRI Syariah Syariah mampu mendapatkan penghasilan yang lebih baik sesuai dengan biaya yang dikeluarkan.

e. Rasio Liquidity (Kemampuan Menjamin Likuiditas)

Rasio likuiditas digunakan untuk menilai kemampuan bank untuk membayar semua hutangnya terutama pada simpanan tabungan, giro dan deposito pada saat ditagih dan dapat pula memenuhi semua permohonan kredit yang layak untuk dibiayai. Dalam hal ini, rasio yang digunakan untuk mengukur tingkat kemampuan bank dalam hal likuiditas adalah rasio Financing to Deposit Ratio (FDR).

Dari hasil perhitungan di atas, rasio Financing to Deposit Ratio (FDR) BRI Syariah tahun 2018 memperoleh nilai sebesar 75,74\% dengan nilai kredit sebesar 157,04\%. Sedangkan pada tahun 2019, rasio Financing to Deposit Ratio (FDR) naik menjadi 80,25\% dengan nilai kredit sebesar 139\%. Hal ini menunjukkan bahwa rasio Financing to Deposit Ratio pada BRI Syariah periode 2018 dan 2019 dapat dikategorikan "sehat" karena nilai rasionya tidak melebihi batas maksimal ketentuan dari Bank Indonesia yaitu sebesar 94,75\% dan nilai kreditnya diatas 100\%. Oleh karena itu, dalam hal ini BRI Syariah dapat memenuhi kewajibannya terutama dalam membayar kembali penarikan dana yang dilakukan oleh deposan/nasabah dan dapat pula memenuhi semua permohonan kredit yang layak untuk dibiayai.

\section{KESIMPULAN}

Dari hasil dan pembahasan mengenai analisis CAMEL pada BRI Syariah periode 2018 dan 2019, dapat disimpulkan bahwa:

1. Rasio Capital Adequacy Ratio (CAR) BRI Syariah tahun 2018 sebesar 29,72\% dengan nilai kredit sebesar 289\% . Lalu, pada tahun 2019 rasio Capital Adequacy Ratio (CAR) sebesar 25,29\% dengan nilai kredit sebesar 253,9\%. Hal ini menunjukkan bahwa BRI Syariah jika dilihat dari segi CAR-nya, bank tersebut memperoleh predikat "sehat".

2. Rasio Kualitas Aktiva Produktif (KAP) BRI Syariah tahun 2018 sebesar $3,93 \%$ dengan nilai kredit 100,27\%. Dan pada tahun 2019, rasio Kualitas Aktifa Produktif (KAP) yang dimiliki oleh BRI Syariah yaitu sebesar 4,08\% dengan nilai kredit 100,12\%. Hal ini menunjukkan 
Analisis Rasio CAMEL (Capital, Asset, Management, Earnings, Equity dan Liquidity) pada Tingkat Kesehatan Bank (Studi Kasus BRI Syariah Periode 2018-2019)

bahwa KAP BRI Syariah pada tahun 2018 dan 2019 memperoleh predikat "sehat".

3. Rasio Net Profit Margin (NPM) BRI Syariah tahun 2018 sebesar 61,20\% dan pada tahun 2019 rasio Capital Adequacy Ratio (CAR) sebesar 29,54\% Hal ini menunjukkan bahwa BRI Syariah jika dilihat dari segi NPM-nya, bank tersebut memperoleh predikat "tidak sehat".

4. Rasio Return on Asset (ROA) BRI Syariah tahun 2018 sebesar 0,4\% dengan nilai kredit sebesar 100,67\%. Lalu, pada tahun 2019 rasio Return on Asset (ROA) sebesar 0,27\% dengan nilai kredit sebesar 101,53\%. Hal ini menunjukkan bahwa BRI Syariah jika dilihat dari segi CAR-nya, bank tersebut memperoleh predikat "tidak sehat". Lalu, rasio BOPO pada BRI Syariah tahun 2018 memperoleh nilai sebesar $56,60 \%$ dengan nilai kredit sebesar 542,5\%. Lalu, pada tahun 2019 rasio BOPO-ya sebesar 60,34 \% dengan nilai kredit sebesar 495,75\%. Oleh karena itu, rasio BOPO pada BRI Syariah periode 2018 dan 2019 dikategorikan "sehat".

5. Rasio Financing to Deposit Ratio (FDR) BRI Syariah tahun 2018 sebesar 75,74\% dengan nilai kredit sebesar 157,04\%. Lalu, pada tahun 2019 rasio Financing to Deposit Ratio (FDR) sebesar 80,25\% dengan nilai kredit sebesar 139\%. Hal ini menunjukkan bahwa BRI Syariah jika dilihat dari segi FDR-nya, bank tersebut memperoleh predikat "sehat". 


\section{REFERENSI}

Hafiz, Ahsan Putra. (2018). Penilaian Tingkat Kesehatan Bank Syariah dengan Metode CAMEL dan REGC (Studi Pada Bank BNI Syariah 2011-2015). Iltizam Journal of Shariah Economic Reseach, 2 (1), 66-67.

Kuniawan, Wawan. (2017, Agustus). "Pengukuran Tingkat Kesehatan PT Bank Rakyat Indonesia (Persero) TBK dengan Metode CAMEL". Media Ekonomi, 25 (2), 80.

Lupa, Wilson, dkk. (2016). "Analisis Perbandingan Tingkat Kesehatan Perbankan Syariah dengan Perbankan Konvensional dengan Metode CAMEL". Jurnal Berkala Ilmiah Efisiensi, 16 (01), 698.

Paputungan, Dwi Febriana. (2016, September) "Penilaian Tingkat Kesehatan Bank Menggunakan Metode CAMEL Pada PT Bank Rakyat Indonesia Cabang Manado Periode 2010-2015". Jurnal EMBA, 4 (3), 733.

Prasetyoningrum, Ari Kristin dan Noor Ahmad Toyyib. (2016, Oktober). "Analisis Tingkat Kesehatan PT Bank BRI Syariah Periode 2011-2014 dengan Menggunakan Metode CAMEL". Economica, 7 (2), 61.

Riyadi, Selamet. (2006). Banking Assets and Liability Management. Jakarta: Lembaga Penerbit Fakultas Ekonomi.

Sari, Nopita. (2018, Agustus). "Analisis Tingkat Kesehatan Bank dengan Menggunakan Metode CAMEL Pada PT BNI Syariah Periode Triwulan Tahun 2015-2017". Islamic Banking, 4 (1), 24.

Syahputra, Randi. (2018, Mei). "Analisis Tingkat Kesehatan Bank dengan Metode CAMEL Pada PT Bank Artos Indonesia Tbk Periode 2014-2017”. Jurnal Akuntansi dan Bisnis, 4 (1), 51.

Undang-Undang Republik Indonesia Nomor 21 Tahun 2008 tentang Perbankan Syariah.

Usman, Rachmadi. (2012). Aspek Hukum Perbankan Syariah di Indonesia. Jakarta: Sinar Grafika. 